This item was submitted to Loughborough's Research Repository by the author.

Items in Figshare are protected by copyright, with all rights reserved, unless otherwise indicated.

\title{
Investigating the outcome of the initial assessment at a national transgender health service: Time to review the process?
}

PLEASE CITE THE PUBLISHED VERSION

https://doi.org/10.1080/15532739.2017.1372838

\section{PUBLISHER}

(C) Taylor \& Francis

\section{VERSION}

AM (Accepted Manuscript)

\section{PUBLISHER STATEMENT}

This work is made available according to the conditions of the Creative Commons Attribution-NonCommercialNoDerivatives 4.0 International (CC BY-NC-ND 4.0) licence. Full details of this licence are available at: https://creativecommons.org/licenses/by-nc-nd/4.0/

\section{LICENCE}

CC BY-NC-ND 4.0

\section{REPOSITORY RECORD}

Jones, Bethany A., Nicola Brewin, Christina Richards, Marnix Van Eijk, Alex Stephenson-Allen, and Jon Arcelus. 2019. "Investigating the Outcome of the Initial Assessment at a National Transgender Health Service: Time to Review the Process?". figshare. https://hdl.handle.net/2134/26855. 
Investigating the outcome of the assessment at national transgender health service:

\section{Time to review the process?}

\section{Abstract}

Background: Globally there is a lack of standardised assessment process prior to the initiation of physical interventions and consequently there is a discrepancy in this process among different transgender health services.

Aim: The main objective of this study is to investigate the outcome of the assessment process at a national transgender health service.

Method: The outcome of people assessed at a large national transgender health service in the UK during a two years period was categorised into: 1) recommendation for hormone treatment, or: 2) no recommendation for hormone treatment. In addition, 200 case-notes were reviewed in order to investigate the level of agreement between the two clinicians involved in the assessment process.

Results: During the studied period a total of 617 people completed their assessment at the service. Following assessment 380 (61.6\%) patients were recommended for hormone treatment and leaving 237 (38.4\%) patients requiring a longer assessment period or being discharged. The factors associated with being recommended for hormone treatment were: having socially transitioned, not smoking, having initiated cross-sex hormones prior to assessment, being older, and assigned male at birth. Out of the 200 case-notes reviewed, agreement between assessor 1 and 2 ( 3 months apart) was found in $88 \%(n=176)$ of the cases.

Discussion: Although the results of the study may not be generalizable to other international centres, questioning the assessment process and the role of the assessors is important to ensure treatment is offered in a timely and efficient manner. The findings from this study suggest that the inclusion of two assessors needs to be reviewed.

Keywords: Assessment, Transgender, Outcome, Cross-sex hormones, Transgender health services 
Investigating the outcome of the assessment at national transgender health service:

\section{Time to review the process?}

\section{Introduction}

In the context of the high demand for transgender health services (de Vries, Krekels, T'Sjoen, Ålgars, \& Mattila, 2015) and the predicted increase in demand (Arcelus et al., 2015); in addition to the prevalence of mental health problems in treatment seeking transgender people when transgender healthcare cannot be accessed (e.g., Arcelus, Claes, Witcomb, Marshall, \& Bouman, 2016; Bouman et al., 2016; Dhejne, Van Vlerken, Heylens, \& Arcelus, 2016) and the associated costs to health services (Padula, Heru, \& Campbell, 2016); timely access to gender affirmative treatment (whether cross sex hormones and/or surgeries) presents a major healthcare challenge (Joseph, Cliffe, Hillyard, \& Majeed, 2017; Reisner et al., 2016). However there is growing evidence that has found gender affirming interventions to increase well-being (e.g., decrease in levels of anxiety and depression; Bouman et al., 2016; Dhejne et al., 2016; Millet, Longworth, \& Arcelus, 2016). In light of the positive effects of gender affirmative interventions, there is a need for innovative strategies to address unmet need and to improve access to gender affirming treatments (Reisner et al., 2016).

Health services for transgender people are guided by the World Professional Association for Transgender Health Standards of Care, $7^{\text {th }}$ edition (SOC-7; Coleman et al., 2012). The SOC-7 describes the need to gather the following information as part of the assessment process: assessment of gender identity and gender dysphoria, history and development of gender dysphoric feelings, the impact of stigma attached to gender diversity on mental health, and the availability of support from family, friends, and peers (Coleman et al., 2012). Possibly due to the lack of empirical evidence regarding the assessment process, the SOC-7 does not provide guidance on the number of appointments the assessment process should be made up of and/or the number of clinicians that should be involved in the assessment process. As a consequence, there is not a standardised procedure that outlines the process of assessing a person who has been referred to a transgender 
health service and therefore is great variation in assessment processes followed among services worldwide.

As in many European countries, in the United Kingdom (UK) health services, including those for transgender people, are state funded. Currently there are seven transgender health services for people 18 years and older in the UK. Recently, these seven services have experienced an increase in demand. For example, the Nottingham Centre of Transgender Health, a nationally commissioned centre that offers care and treatment to people living in England and Wales, received 1030 referrals in 2016 which was double the number of referrals in $2015(n=530)$ and dramatically more than in $2014(n=230)$ and $2013(n=120)$. This increase in demand is not unique to this centre as a similar pattern has been describes by other centres within and outside the UK (de Vries et al., 2015; House of Commons., 2016). As a consequence of the increase in referral rates, extremely long waiting times to access state funding transgender health services in the UK have been experienced by many. Currently within the UK there are more than 5000 people waiting to be assessed with the average waiting times being over 2 years.

Currently the assessment process offered at most transgender health services within England and Wales takes place over at least two appointments and involves two independent professionals. As part of the assessment process, mental health needs are considered but these would not usually prevent a recommendation for gender affirmative treatment (SOC-7; Coleman et al., 2012). Gender identity is also assessed - this being a psychological identification of oneself or the internal sense of being in relation to gender. How people feel about their gender is, of course, very personal (Bouman \& Arcelus, 2017) and only the individual truly knows how they feel about their gender (Coleman et al., 2012). In view of this, assessing an individual's gender identity may be unnecessary as they are in the best position to identify their gender. On the other hand, it is important to gather a gender history to exclude the possibility of major mental illnesses that may be presenting as gender dysphoria, albeit uncommon. For instance, a patient with Schizophrenia may hold delusional beliefs 
about their gender and body, which without exploration may be mistreated as gender dysphoria. It is also important that the stability of gender identity and expression is ascertained due to the irreversibility of physical gender affirming interventions. In light of this, state funded transgender health services argue that there is benefit from a decision making process regarding these interventions that involves more than one clinician, despite there being a lack of direct evidence to support that this is best practice.

Due to the lack of studies investigating the outcome of assessments at transgender health services, there is only a very rough consensus between clinicians and transgender health services as to what the most appropriate, effective and efficient process should be. Clinical practice should always be informed by empirical evidence (e.g., Sackett, Rosenberg, Gray, Haynes \& Richardson, 1996) and therefore more research is warrant in exploring the best practice regarding assessment at transgender health services. This research should begin by investigating what the outcome of the current assessment process is. Such knowledge will inform initiatives to facilitate with improving and standardising the assessment process at transgender health services. In view of this, the main objective of this study is to investigate the outcome of the assessment process at a large national transgender health service in the UK. The study has several specific aims: First, to describe the different recommendations made by clinicians following assessment. Second, to compare patients who had and had not been recommended for the treatment programme on pre-assessment variables. Lastly, the study will investigate the levels of agreement between the two clinicians involved in the assessment process in order to investigate whether a second clinician aids the assessment outcome. 


\section{Method}

\section{Recruitment and participants}

The study took place at the Nottingham Centre for Transgender Health within the National Health Service (NHS) in the United Kingdom. This is one of the largest clinics of its kind in Europe and receives more than 1000 referrals a year from people living in England and Wales. As per other UK services, referrals to the service are received mainly from primary care as well as secondary care. People cannot self-refer to this service. The routine assessment process consists of two separate appointments with two independent senior clinicians of 90 minutes each and a third appointment involving both clinicians, plus the individual being assessed. A significant other can be invited by the patient into the third appointment. There is usually a gap of 3 months between each assessment appointment. Due to capacity issues, patients can expect to wait approximately 2 years after the referral for the assessment process to begin, which is clearly unacceptable. The service accepts referrals of people aged 17 and over with a number of referrals being transferred from the NHS Gender Identity Development Service (the child and adolescent service) in London or Leeds. Following the assessment, a decision is made as to whether the individual is ready and suitable to enter into the treatment programme (e.g., prescription of cross-sex hormone treatment). In order for transgender people to be accepted into the programme, it is usual for people to amend most of their legal documentation, including changing their name, which is a straight forward process in the UK. Aside from the assessment considerations detailed above, if there are no physical contraindications patients who wish to, will be prescribed cross-sex hormone treatment. Following a minimum of 6 months of living in their gender role, transgender males can then be considered for chest reconstructive surgery. Transgender males and females wishing to undergo genital surgery will usually live in their gender role for a minimum of one year and will usually have taken hormones during that time. 


\section{Procedure}

For the first aim of the study, the clinical notes of all patients assessed at the centre during a twoyear period (2014-2016) were examined. The outcome of the assessment was coded into two main groups: 1) immediate recommendation to enter into treatment programme (or direct access to treatment- DAT), or; 2 ) not recommended to enter into treatment programme (no direct access to treatment- NDAT). For the second aim, socio-demographic characteristics, including age and assigned sex as well as transitional status pre-assessment (coming out to others, name change, social gender role transition) was collected and both groups (DTA and NDTA) were compared on these variables. For the last aim, a sample of randomly selected active case-notes was examined ( $n$ 200). The recommendations made by the first and second assessor in each case were coded into the same two categories used in the first aim (DAT and NDAT). Where disagreement between assessors in the outcome recommended was identified, factors (socio-demographics) associated with disagreement were explored. These factors included age at the time of referral and at assessments, ethnic origin, assigned sex, and gender identity.

The study was a part of a longitudinal study, which received ethical approval from the NHS Ethics committee and from the Research and Development Department from the Nottinghamshire Healthcare NHS Foundation Trust in line with Health Research Authority guidance (HRA, 2013).

\section{Data analysis}

All quantitative data analyses were performed using SPSS 22 (IBM, 2013). First, descriptive statistics were examined. Data were positively skewed in both groups (DAT and NDAT) and non-normally distributed, as demonstrated by significant $(p=.002)$ Kolmogorov-Smirnov tests. Therefore, nonparametric tests were selected. For comparison between groups, Mann-Whitney $\mathrm{U}$ tests and Chisquare tests were conducted. The level of significance used was $p<0.05$. 


\section{Results}

\section{Aim 1: outcome of the assessment process}

During the studied period a total of 617 people completed their assessment at the service. Following assessment $380(61.6 \%)$ were recommended direct access to hormone treatment (DAT). A total of 237 (38.4\%) people were not recommended direct access to hormone treatment (NDAT). In the majority of the cases where treatment was not initiated (or immediately initiated) the reasons were related to requiring a longer assessment process ( $n=97,40.9 \%$ of NDAT), not providing evidence of a social gender role transition, including change of name $(n=52,53.6 \%$ of the group requiring longer assessment). In 11 (4.6\%) cases, psychotherapy was recommended, while 12 (5.1\%) people did not attend the second appointment and therefore were discharged from the service. For nearly $40 \%$ of the cases $(n=93,39.2 \%)$ medical transition was not felt to be appropriate due to personal factors (such as non-acceptance from partners and complexities surrounding this) and asked to be discharged from the service. Following assessment, $24(10.1 \%)$ of the NDAT group were unclear about their gender and felt that transition was not necessary.

\section{Aim 2: comparing DAT to NDAT on pre-assessment socio-demographic variables}

The mean age for the whole group was 30.65 years $(S D=14.03)$ with a minimum of 17 years and a maximum of 79 . People not offered direct access to treatment appeared older (mean=31.65, $S D=$ 14.20) than people in the DAT group (mean=30.02 $S D=13.90$ ) however, the difference between groups was not significant $(\mathrm{U}=40944.00, \mathrm{z}=-1.90, p=.057)$. A Chi-square test indicated significant association between assigned gender and direct access to treatment with more people assigned male at birth than assigned female at birth being offered direct access to the treatment programme (DAT; see Table 1). In the NDAT group there was bigger number of people who were described as a smoker; who had not come out as transgender; and who had not made a social gender role transition in comparison to the DAT group pre-assessment (see Table 1). Additionally, people who had taken hormones pre-assessment were significantly more likely to be recommended for the 
initiation of gender affirming interventions after the assessment process than people who had not taken hormones pre-assessment (see Table 1). Information was not available for 4 cases.

Insert Table 1 around here
Comment [B] 1]: Was this just for this analysis? Because in the Table the group sizes for the DAT and NDAT groups are the same as they are for the first aim (380 4

Aim 3: Discordance between the outcome of first and second assessor for entry into the treatment programme

Out of the 200 case notes reviewed, agreement between assessor 1 and 2 ( 3 months apart) was found in $88 \%(n=176)$ of the cases. In most cases $(n=23,95.8 \%)$ disagreement between assessor 1 and 2 was present because in the first assessment appointment the patient had not made a social gender role transition (and therefore did not recommended initiation of gender affirmative treatments) but in the second appointment with assessor two, a social gender role transition had been made. There was only one case where the first assessor recommended treatment but not the second assessor. Of the patients with discordant assessment recommendations, the majority (80\%) were people assigned male at birth and in both instances a difference in treatment recommendations were found for people assigned female at birth this was related to obtaining documents in the interim. No significant trends were identified in the other socio-demographic data collected.

\section{Discussion}

This study aimed to investigate the outcome of the assessment process at a large national transgender health service in the UK and explore factors associated with people who were and were not recommended for the treatment programme. It was hoped that obtaining this information would inform the development of initiatives to facilitate with improving the assessment process (i.e., making it more efficient) as well as standardising the assessment process. The findings from this study demonstrated that more than half of the people assessed at this large national centre in the 
UK were recommended for treatment following routine assessment. The reasons for why treatment was not recommended were associated with the person not changing their legal documents, including name. Socially transitioning before physical gender affirming interventions is not mandatory in some transgender health services and not a requirement stipulated by the SOC-7 (Coleman et al., 2012). However, clinicians at the Nottingham Centre for Transgender Health (and in many other centres in the UK) feel that it is important that people first make a social gender role transition to determine how this will be orchestrated and be accepted by the person themselves and others around them, prior to irreversible interventions being offered. This requirement once again lacks evidence and future studies should investigate the role of socially transitioning prior to crosssex hormones has on outcomes.

The current study also demonstrated that the in the majority of the cases both assessors involved in the assessment process agreed regarding recommendation for physical gender affirming interventions. Due to the high level of agreement, the need for two different assessors in the assessment process should be questioned. Having one assessor would facilitate with decreasing waiting times at transgender health services. Once again the involvement of two different assessors for interventions other than genital surgery is not evidence based and not a requirement stipulated by SOC-7 (Coleman et al., 2012). At the Nottingham Centre for Transgender Health, levels of expertise and seniority at this centre is very high which may result in higher levels of agreements between assessors; and therefore transgender health services with more junior staff may have different findings. In these circumstances, having two assessors may be appropriate although further research is required.

To facilitate with improving the assessment process at transgender health services, being able to differentiate between people who are ready for hormone treatment from those who are not, is important. So far this study is able to demonstrate that people who have socially transitioned, do 
not smoke, are on cross sex hormones, are older, and are assigned male at birth (mainly related to social transition) pre-assessment are more likely to be recommended for the treatment programme following the assessment process than people who have not socially transition, smoke, have not taken cross-sex hormones, are younger and assigned female at birth pre-assessment. Services where social transitioning pre-treatment is not a requirement may have an even higher number of people entering the treatment programme for initiation of cross-sex hormones. Future factors such as the role of social support (Bouman, Davey, Meyer, Witcomb, \& Arcelus, 2016; Davey, Bouman, Arcelus, \& Meyer, 2014); age (Arcelus et al., 2016); and certain characteristics such as features of autistic spectrum found to be high among this population (Glidden, Bouman, Jones, \& Arcelus, 2016) could also be considered in future studies. Future studies may also investigate the role of assessment in reaching diagnostic criteria in view of the future ICD-11 diagnosis (Beek et al., 2016).

The majority of the disagreement between assessors in recommendation for the treatment programme found in the current study could be influenced by temporal factors, as opposed to the fact that assessments were undertaken separately by two senior clinicians. It may well be that the first assessment acted as a 'spur' to act (i.e., make a social gender role transition); but given the nature of the pressures on the service, thought must be given to the assessment process with a view to increasing patient throughput, but without increasing the risk of harm to patients by recommending inappropriate interventions. Indeed, it is worth considering that as the Nottingham Centre for Transgender Health is an NHS (taxpayer funded) service, there is an expectation that the treatment bring with it significant benefit - rather than simply the lack of harm which may be the basis of some systems where the patient themselves pays for treatment. Further, long-term outcomes from gender affirming treatment has not been well studied and has mainly focussed on mental health (e.g., Davis \& Meier et al., 2014; De Cuypere, Elaut, Heylens \& Monstrey, 2006; Heylens, Verroken, De Cock, T'Sjoen \& De Cuypere, 2014). Rates of 'regrets' with transition indicated by a wish to de-transition back to assigned gender are rare and there is no evidence that a 
prolonged assessment process improves outcome (regarding mental health) or reduces regret (e.g., Lawrence, 2003). Although the results of the study may not be generalizable to other international centres, especially those which are not taxpayer funded, questioning the assessment process and the role of the assessors in the field of transgender health is important. The role of assessment, as well as investigating ways of increasing the efficiency of the process, needs to be examined. 


\section{References}

Arcelus, J., Bouman, W. P., Van Den Noortgate, W., Claes, L., Witcomb, G., \& Fernandez-Aranda, F.

(2015). Systematic review and meta-analysis of prevalence studies in transsexualism. Eur

Psychiatry, 30(6), 807-815. doi:10.1016/j.eurpsy.2015.04.005

Arcelus, J., Claes, L., Witcomb, G. L., Marshall, E., \& Bouman, W. P. (2016). Risk factors for non-

suicidal self-injury among trans youth. Journal of Sexual Medicine, 13(3), 402-412.

doi:10.1016/j.jsxm.2016.01.003

Beek, T. F., Cohen-Kettenis, P. T., Bouman, W. P., de Vries, A. L., Steensma, T. D., Witcomb, G. L., . . Kreukels, B. P. (2016). Gender Incongruence of Adolescence and Adulthood: Acceptability and Clinical Utility of the World Health Organization's Proposed ICD-11 Criteria. PLoS One, 11(10), e0160066. doi:10.1371/journal.pone.0160066

Bouman, W. P., \& Arcelus, J. (2017). The Transgender Handbook: A guide for professionals, transgender people and their families New York: Nova.

Bouman, W. P., Claes, L., Brewin, N., Crawford, J. R., Millet, N., Fernandez-Aranda, F., \& Arcelus, J.

(2016). Transgender and anxiety: A comparative study between transgender people and the general population. International Journal of Transgenderism, 18(1), 16-26. doi:10.1080/15532739.2016.1258352

Bouman, W. P., Claes, L., Marshall, E., Pinner, G. T., Longworth, J., Maddox, V., . . Arcelus, J. (2016). Sociodemographic Variables, Clinical Features, and the Role of Pre-assessment Cross-Sex Hormones in Older Trans People. The Journal of Sexual Medicine, 13(4), 711-719. doi:10.1016/j.jsxm.2016.01.009

Bouman, W. P., Davey, A., Meyer, C., Witcomb, G. L., \& Arcelus, J. (2016). Predictors of psychological well-being among treatment seeking transgender individuals. Sexual and Relationship Therapy, 1-17. doi:10.1080/14681994.2016.1184754

Coleman, E., Bockting, W., Botzer, M., Cohen-Kettenis, P., DeCuypere, G.,...Zucker, K. (2012). Standards of Care for the Health of Transsexual, Transgender, and Gender-Nonconforming 
People, Version 7. International Journal of Transgenderism, 13(4), 165-232. doi:

org/10.1080/15532739.2011.700873

Davey, A., Bouman, W. P., Arcelus, J., \& Meyer, C. (2014). Social support and psychological wellbeing in gender dysphoria: a comparison of patients with matched controls. The Journal of Sexual Medicine, 11(12), 2976-2985. doi:10.1111/jsm.12681

Davis, S. A., \& Meier, S. (2014). Effects of testosterone treatment and chest reconstruction surgery on mental health and sexuality in female-to-male transgender people. International Journal of Sexual Health, 26(2), 113-128. doi: org/10.1080/19317611.2013.833152

De Cuypere, G., Elaut, E., Heylens, G., \& Monstrey, S. (2006). Long-term follow-up: Psychosocial outcome of Belgian transsexuals after sex reassignment surgery. Sexologies, 15(2), 126-133. doi:10.1016/j.sexol.2006.04.002

de Vries, A. L. C., Kreukels, B. P. C., T’Sjoen, G., Ålgars, M. \& Mattila, A. (2015). Increase of referrals to gender identity clinics: A European trend? In: Transgender Healthcare in Europe. Book of Abstract. pp10. Ghent, Belgium: European Professional Association of Transgender Health (EPATH). Retrieved online from http://epath.eu/wp-content/uploads/2014/07/EPATH-2015Book-of-Abstracts.pdf on 8th April 2015

Dhejne, C., Van Vlerken, R., Heylens, G., \& Arcelus, J. (2016). Mental health and gender dysphoria: A review of the literature. International Review of Psychiatry, 28(1), 44-57. doi:10.3109/09540261.2015.1115753

Glidden, D., Bouman, W. P., Jones, B. A., \& Arcelus, J. (2016). Gender Dysphoria and Autism Spectrum Disorder: A Systematic Review of the Literature. Sexual Medicine Reviews, 4(1), 314. doi:10.1016/j.sxmr.2015.10.003

Heylens, G., Verroken, C., De Cock, S., T'Sjoen, G., \& De Cuypere, G. (2014). Effects of different steps in gender reassignment therapy on psychopathology: a prospective study of persons with a gender identity disorder. Journal of Sexual Medicine, 11(1), 119-126. doi: 10.1111/jsm.12363 
House of Commons. (2016). Transgender Equality Inquiry: First report of session 2015-16. London:

The Stationery Office Limited. Retrieved from:

http://www.publications.parliament.uk/pa/cm201516/cmselect/cmwomeq/390/39002.htm

IBM. (2013). IBM SPSS Statistics for Windows, Version 22.0. Armonk, NY: IBM Corp

Joseph, A., Cliffe, C., Hillyard, M., \& Majeed, A. (2017). Gender identity and the management of the transgender patient: a guide for non-specialists. Journal of the Royal Society of Medicine, 110(4), 144-152. doi:10.1177/0141076817696054

Lawrence, A. A. (2003). Factors associated with satisfaction or regret following male-to-female sex reassignment surgery. Archives of Sexual Behavior, 32(4), 299-315.

Millet, N., Longworth, J., \& Arcelus, J. (2016). Prevalence of anxiety symptoms and disorders in the transgender population: A systematic review of the literature. International Journal of Transgenderism, 18(1), 27-38. doi:10.1080/15532739.2016.1258353

Padula, W. V., Heru, S., \& Campbell, J. D. (2016). Societal Implications of Health Insurance Coverage for Medically Necessary Services in the US Transgender Population: A Cost-Effectiveness Analysis. Journal of General Internal Medicine, 31(4), 394-401. doi:10.1007/s11606-015$3529-6$

Reisner, S. L., Poteat, T., Keatley, J., Cabral, M., Mothopeng, T., Dunham, E., . . Baral, S. D. (2016). Global health burden and needs of transgender populations: a review. Lancet, 388(10042), 412-436. doi:10.1016/S0140-6736(16)00684-X

Sackett, D. L., Rosenberg, W. M., Gray, J. M., Haynes, R. B., \& Richardson, W. S. (1996). Evidence based medicine: what it is and what it isn't. $B M J, 312,71-72$. doi: https://doi.org/10.1136/bmj.312.7023.71 
Table 1: Chi-square test comparing people who were $(n=380)$ and were not $(n=237)$ recommended for the treatment programme after the assessment process on pre-assessment socio-demographic variables

\begin{tabular}{|c|c|c|c|}
\hline & $\begin{array}{l}\text { DAT patients } \\
\qquad(n=380)\end{array}$ & $\begin{array}{l}\text { NDAT patients } \\
(n=237)\end{array}$ & $x^{2}$ \\
\hline & \multicolumn{2}{|c|}{ Sample size (\%) } & \\
\hline Mean (SD) age & $30.02(13.90)$ & $31.65(14.20)$ & \\
\hline Assigned female & 167 (74.22\%) & $58(25.77 \%)$ & \\
\hline Assigned male & $213(54.33 \%)$ & $179(45.66 \%)$ & $23.89 * * *$ \\
\hline Smoker & $44(49.43 \%)$ & 45 (50.56\%) & \\
\hline Non-smoker & $336(63.63 \%)$ & $192(36.36 \%)$ & $6.49 * *$ \\
\hline Hormones & $130(81.25 \%)$ & $30(18.75 \%)$ & \\
\hline No hormones & 245 (54.68\%) & $203(45.31 \%)$ & $41.42 * * *$ \\
\hline Come out as transgender & $324(66.52 \%)$ & $163(33.47 \%)$ & \\
\hline Not come out as transgender & $56(43.07 \%)$ & $74(56.92 \%)$ & $23.85^{* * *}$ \\
\hline Social gender role transition & 218 (77.30\%) & $64(22.69 \%)$ & \\
\hline Not made a social gender role transition & $162(48.35 \%)$ & 173 (51.64\%) & $54.23 * * *$ \\
\hline
\end{tabular}

${ }^{*} p<0.05,{ }^{* *} p<0.01,{ }^{* * *} p<0.001$; DAT=Direct access to hormone treatment, NDAT $=$ No direct access to hormone treatment 